STUDI

FRANCESI

\section{Studi Francesi}

Rivista quadrimestrale fondata da Franco Simone

165 (LV | III) | 2011

LA RAPPRESENTAZIONE DELLA MADRE NELLA

LETTERATURA FRANCESE DEL NOVECENTO a cura di Dario Cecchetti e Michele Mastroianni

\title{
Le Rire ou le Modèle? Le Dilemme du moraliste, textes réunis par Jean Dagen et Anne-Sophie Barrovecchio
}

\author{
Andrea Schellino
}

\section{(2) OpenEdition \\ Journals}

\section{Edizione digitale}

URL: http://journals.openedition.org/studifrancesi/5192

DOI: $10.4000 /$ studifrancesi.5192

ISSN: 2421-5856

\section{Editore}

Rosenberg \& Sellier

\section{Edizione cartacea}

Data di pubblicazione: 1 décembre 2011

Paginazione: 698-699

ISSN: 0039-2944

Notizia bibliografica digitale

Andrea Schellino, «Le Rire ou le Modèle? Le Dilemme du moraliste, textes réunis par Jean Dagen et AnneSophie Barrovecchio», Studi Francesi [Online], 165 (LV | III) | 2011, online dal 30 novembre 2015, consultato il 07 janvier 2021. URL: http://journals.openedition.org/studifrancesi/5192 ; DOI: https:// doi.org/10.4000/studifrancesi.5192

Questo documento è stato generato automaticamente il 7 janvier 2021.

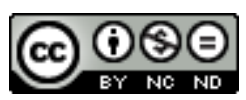

Studi Francesi è distribuita con Licenza Creative Commons Attribuzione - Non commerciale - Non opere derivate 4.0 Internazionale. 


\title{
Le Rire ou le Modèle? Le Dilemme du moraliste, textes réunis par Jean Dagen et Anne-Sophie Barrovecchio
}

\author{
Andrea Schellino
}

\section{NOTIZIA}

AA. VV., Le Rire ou le Modèle? Le Dilemme du moraliste, textes réunis par Jean DAGEN et AnneSophie BARRovecCHIO, Paris, Champion, 2010, pp. 699.

1 Il ponderoso volume curato da Jean DAGEN e da Anne-Sophie BARROVECCHIO, raccoglie una vasta selezione di saggi dedicati alle esemplarità e al riso dei moralisti francesi tra il XV e il XVIII secolo, senza dimenticare alcune proposte filosofiche e letterarie (Democrito, Agostino, Lucrezio, Pascal, Descartes, Bayle, Corneille, Molière...) che si intersecano con i modelli proposti all'alba della modernità. Nel confronto con i due poli del riso e dell'esemplarità classica, infatti, come scrive Jean Dagen nella sua Préface (pp. 7-16), si misura l'abilità del moralista di proporre modelli di comportamento e di ordine sociale. Così, mentre Montaigne nei suoi Essais si persuade che la saggezza non ha bisogno di modelli antichi, nel suo capolavoro sul filo dei capitoli si affollano esempi, personaggi e aneddoti della storia e della letteratura della Grecità e della Romanità; e, parimenti, le esemplarità antiche e cristiane, con il loro inesauribile bagaglio di virtù e valori cristallizzati, pervadono le scritture dei moralisti cinquecenteschi e secenteschi. In quest'ottica, numerosi contributi del volume sono dedicati ai modelli offerti da Plutarco e Lucrezio, mentre altri si soffermano invece sulla messa in discussione dell'exemplum tradizionale.

2 Nella loro irreprensibile fedeltà all'Idea del Vero e del Giusto, che non viene meno neppure quando le loro penne fustigano impietosamente le imperfezioni e le manchevolezze dell'uomo, i moralisti guardano con sospetto l'attitudine comica e satirica: «La Bruyère, on le sait, condamne la raillerie; pour La Rochefoucauld "ridicule" 
signifie tout au plus déraisonnable» (p.14); in loro non troviamo nessun riso rabelesiano, volterriano o nietzschiano a scuotere la certezze. Per udire questo riso, dobbiamo pertanto spostarci su un versante filosofico-ma, si badi bene, come attitudine, non come mestiere-che provoca, sorprende e mette in cammino; un'esigenza proseguita, nel Novecento, nell'aforisticità paradossale dei Blanchot e dei Cioran.

3 Da Chamfort, ad esempio, il riso, satira d'ogni fatticità, è descritto come «hommage à la nature»; nelle opere di Pascal non mancano affatto gli scoppi di risa; a teatro e nella letteratura del volgere del Settecento l'istruzione passa anche attraverso la burla e la beffa (castigare ridendo mores). Il volume si chiude proprio con un interessante trittico di testi, scritti da Louis VAN DELF, da Anne-Sophie BARROVECCHIO e da Jean DAGEN, sui rires philosophiques.

4 Ecco gli autori e i titoli dei singoli contributi, di cui non si può qui dar conto singolarmente: Françoise FRAZIER, Histoire et exemplarité: les «hommes de Plutarque» (pp. 21-37), Olivier GUERRIER, Le «miroir», de Plutarque à Montaigne (pp. 39-55), MarieDominique COUZINET, «Magistra vitae»: Histoire et exemplarité au XVI siècle (pp.57-88), Hélène MERLIN-KAJMAN, L'exemplarité romaine, entre la tragédie et la farce (pp. 89-107), Charles-Olivier STIKER-MÉTRAL, Valeurs et usages des vertus antiques: les métamorphoses de "La Cité de Dieu" d'Augustin à Rousseau (pp. 109-127), Michel BOUvier, De l'exemple au portrait: "Le portrait d'une femme honnête" de l'abbé Goussault (pp. 129-144), Emmanuelle HÉNIN, L'Exemple de Lucrèce dans la peinture, du XV $v^{e}$ au XVIII siècle (pp.147-162; questo contributo è corredato di un appendice di sedici tavole illustrate), Marc ESCOLA, Fallait-il qu'elle mourût? La "Lucrèce" de Du Ryer (pp. 163-181), Françoise GEVREY, L'exemplarité de Lucrèce dans "Clélie" (pp.183-198), Julie восн, Exemple historique, jurisprudence morale: Lucrèce chez Bayle (pp.199-218), Catherine FRANÇoIS-GIAPPICONI, Lucrèce sur la scène française: les avatars d'une figure féminine exemplaire dans les œuvres dramatiques des XVII et

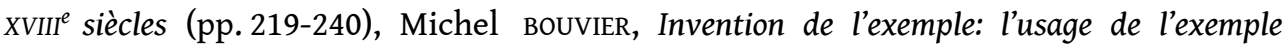
inventé et sa signification de Montaigne à La Bruyère (pp. 243-272), Mariafranca SPALLANZANI, "La vie retirée» de Descartes: entre exemplarité et singularité (pp. 273-302), Claudine poulouin, Bayle et la problématisation de l'exemple dans le "Dictionnaire Historique et Critique" (pp. 303-327), Carole DORNIER, De Versac à Chester: l'évolution de la figure exemplaire du séducteur libertin chez Crébillon (pp. 329-344), Pierre самBоU, Du conte voltairien et du récit exemplaire d'après "Les Deux consolés" (pp.345-357), Laurent THIRouIN, Éclats de rire pascaliens (pp. 363-390), Mariel BOURGEOIs, Visages du rire dans les "Pensées" (pp. 391-408), Michel BOUVIER, Le rire entre le corps et l'âme (pp. 409-431), Pierre CAHNÉ, Le rire de Corneille (pp. 435-443), Dominique QUÉRO, Les audiences du moraliste: rire et satire dans les «pièces à tiroirs» (pp. 445-462), Sophie MARCHAND, Du rieur au Philosophe: Molière au XVIII siècle sous la plume de Grimarest, Goldoni et Mercier (pp. 463-485), Dominique BERTRAND, L'imaginaire du rire dans "Les Caractères" de La Bruyère (pp. 489-520), Carole DORNIER, Des dangers de la raillerie et de la corruption des mours (pp.521-537), Daniel ACKE, Le rire du prince de Ligne (pp.539-556), Cyril LE MEUR, Deux échos d'un rire fin de siècle: Chamfort et Rivarol (pp. 557-579), Sophie BÉNÉZIT, Le conteur qui voulait être moraliste: pour une illustration du castigare ridendo mores (pp. 581-596), Laurence VANOFLEN, Le rire est-il encore possible à la fin du XVIII siècle? (pp.597-607), Louis VAN DELFT, La défaite de Démocrite (pp. 611-629), Anne-Sophie BARROVECCHIO, Hylaire, cousin de "Bélisaire": une parodie pour rire de l'avocat 
Marchand (1767) (pp.631-649), Jean DAGEN, Que philosopher c'est apprendre à rire (pp. 651-670). 